\title{
Copper Nanoparticles on Controlled Pore Glass and TEMPO for the Aerobic Oxidation of Alcohols
}

\author{
Ismail Ibrahem, ${ }^{*\left[{ }^{[b]}\right]}$ Muhammad Naeem Iqbal ${ }^{[a, c]}$ Oscar Verho, ${ }^{[a]}$ Alireza Eivazihollagh, ${ }^{[b]}$ \\ Peter Olsén, ${ }^{[a]}$ Håkan Edlund, ${ }^{[b]}$ Cheuk-Wai Tai, ${ }^{[c]}$ Magnus Norgren, ${ }^{*[b]}$ and Eric V. Johnston ${ }^{*[d]}$
}

\begin{abstract}
Herein, we report on the facile synthesis of a heterogeneous copper nanocatalyst and its combination with 2,2,6,6-tetramethyl-1-piperidinyloxy (TEMPO) for the aerobic oxidation of alcohols to their corresponding carbonyl compounds. This low cost copper nanocatalyst was found to exhibit excellent recyclability, making it a highly attractive catalytic system from an economical and environmental point of view. Extensive characterization of the catalyst by a number of techniques revealed that it was comprised of well-dispersed $\mathrm{Cu}(\mathrm{I} / \mathrm{II})$ nanoparticles with an average size of around $6 \mathrm{~nm}$.
\end{abstract}

Transition-metal catalysis has revolutionized the field of organic synthesis by improving the efficiency and selectivity of many different reactions, as well as opening up reaction pathways that are inaccessible using conventional chemistry. ${ }^{[1]}$ In recent years, transition metal nanoparticles have gained particular popularity within the organic synthesis community as they have shown excellent catalytic activity for a variety of chemical transformations. ${ }^{[2]}$ Of these nanoparticle-based catalysts, those based on immobilized metal nanoparticles are of special interest as they display improved stability and simpler separation from the reaction mixture, which allows for effective recycling. Furthermore, by employing heterogeneously supported nanoparticles it is easier to minimize the levels of metal impurities in the final product, which is a topic of major concern for synthetic processes within the pharmaceutical industry. ${ }^{[3]}$

[a] M. N. lqbal, Dr. O. Verho, Dr. P. Olsén

Department of Organic Chemistry, Arrhenius Laboratory, Stockholm University, SE-106 91 Stockholm, Sweden

[b] Dr. I. Ibrahem, A. Eivazihollagh, Prof. H. Edlund, Prof. M. Norgren

FSCN, Surface and Colloid Engineering, Mid Sweden University, SE-851 70 Sundsvall, Sweden

E-mail: ismail.ibrahem@miun.se magnus.norgren@miun.se

[c] M. N. Iqbal, Dr. C.-W. Tai

Department of Materials and Environmental Chemistry, Arrhenius Laboratory, Stockholm University, SE-106 91, Stockholm, Sweden

[d] Dr. E. V. Johnston

Sigrid Therapeutics, Universitetsvägen 8 (Villa Bellona), SE-106 91, Stockholm, Sweden

E-mail: eric@sigridthx.com

Supporting information for this article is available on the WWW under https://doi.org/10.1002/cnma.201700309
The rapid development of the nanocatalysis field has primarily been driven by advances in material and nanotechnology research. Today, a wide variety of well-elaborated synthetic protocols are available that allow precise tailoring of the chemical and physical properties of metal nanoparticles, including their particle size, shape, composition, and chemical state. ${ }^{[4]}$ Moreover, there exists a great number of different supports that can be prepared with tunable morphology and specific surface functionalization, including carbon-based materials, $^{[5]}$ covalent-organic frameworks, ${ }^{[6]}$ metal-organic frameworks, ${ }^{[7]}$ metal oxides, ${ }^{[8]}$ polymers ${ }^{[9]}$ and silicas. ${ }^{[10]}$ In this context, controlled pore glass (CPG), which belongs to the family of silica-based materials, remains a relatively underutilized support within the nanocatalysis field. Aside from possessing the typical characteristics of silica supports, such as cost-effective synthesis, tunable morphology and being commercially available with different types of surface functionalities, CPG also exhibits remarkable chemical and thermal stability, making it an excellent choice for the immobilization of various transition metal catalysts. The limited numbers of studies that have used CPG, mainly describe its use as a support for nanopalladium and nanoplatinum based catalysts. ${ }^{[11]}$

Given the surging interest in green and sustainable oxidation catalysis, we were motivated to explore the possibility of using CPG as a support for copper nanoparticles, and to investigate if the developed catalyst could be effective in mediating the oxidation of alcohols to their corresponding carbonyl compounds. Indeed, there are several homogeneous copper/TEMPO co-catalyzed systems available for the oxidation of alcohols; ${ }^{[12]}$ however, the number of heterogeneous protocols are markedly fewer. ${ }^{[13]}$ Moreover, the vast majority of the catalytic systems that employ homogeneous copper salts also rely on the use of nitrogen-containing ligands to stabilize the copper and prevent formation of inactive copper oxides. For heterogeneous systems such functionalities can be anchored directly onto the support material, enabling simultaneous recycling of both the stabilizing ligand and the copper catalysts from the reaction mixture.

Herein, we report the straightforward synthesis of mixed $\mathrm{Cu}(\mathrm{I} / \mathrm{II})$ nanoparticles immobilized on aminopropyl-functionalized controlled pore glass ( $\mathrm{Cu}(\mathrm{I} / \mathrm{II})$-AmP-CPG). The copper nanocatalyst was demonstrated to be an efficient catalyst for the oxidation of alcohols to their corresponding carbonyl compounds when used together with TEMPO as an electron transfer mediator under solvent-free conditions. 
A schematic overview of the synthesis of the Cu-AmP-CPG nanocatalyst is outlined in Scheme 1 , and a more detailed

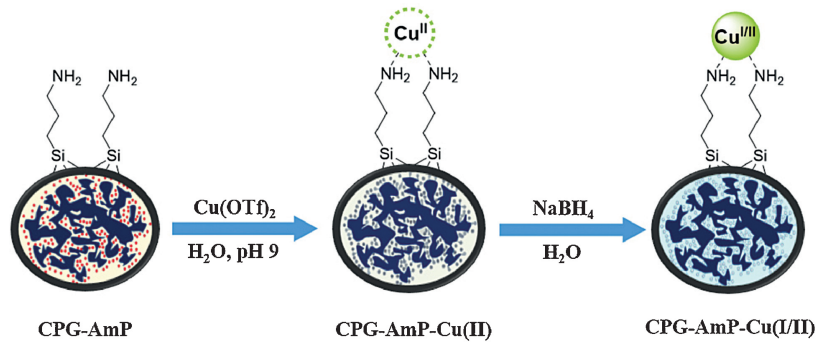

Scheme 1. General scheme for the synthesis of the mixed valence $\mathrm{Cu}(\mathrm{I} / \mathrm{II})$ AmP-CPG catalyst. For clarity reasons, the surface functionalization is depicted on the exterior of the CPG particle, although the majority of these sites are in fact located within the interwoven network of the pores.

experimental procedure is provided in the Supporting Information (SI). Briefly, amino-functionalized CPG (AmP-CPG) was subjected to an aqueous solution of $\mathrm{Cu}(\mathrm{OTf})_{2}(\mathrm{pH} 9)$ at room temperature for $24 \mathrm{~h}$ to furnish a $\mathrm{Cu}(\mathrm{II})$-precatalyst. This precatalyst was subsequently reduced by treatment with 20 equivalents $\mathrm{NaBH}_{4}$ in $\mathrm{H}_{2} \mathrm{O}$ at ambient temperature for 45 min to generate the mixed valence $\mathrm{Cu}-\mathrm{AmP}$-CPG nanocatalyst. The obtained $\mathrm{Cu}$ nanocatalyst was characterized by a number of analytic techniques, including transmission emission microscopy (TEM) coupled with electron energy loss spectroscopy (EELS), scanning electron microscopy (SEM), X-ray photoelectron spectroscopy (XPS) and elemental analysis by inductively coupled plasma optical emission spectrometry (ICP-OES). To determine the size of the supported nanoparticles, TEM was used (Figure 1) and a statistical particle size distribution was

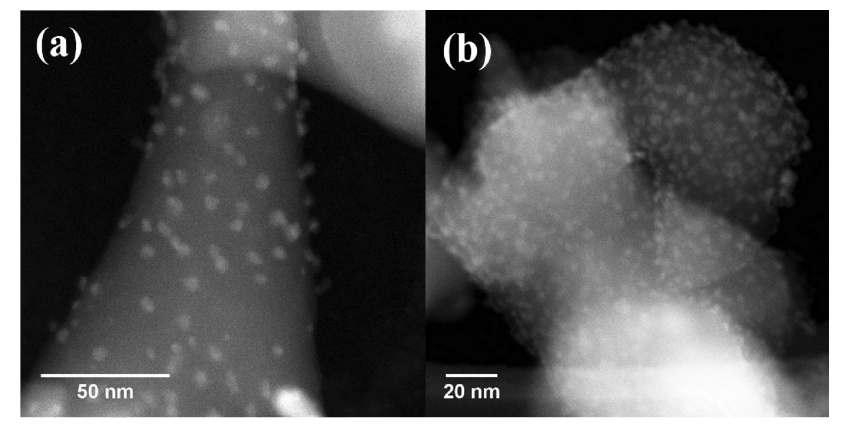

Figure 1. Transmission electron micrographs (dark field imaging) of the mixed valence $\mathrm{Cu}-\mathrm{AmP}$-CPG nanocatalyst, a) with $50 \mathrm{~nm}$ scale bar and b) with $20 \mathrm{~nm}$ scale bar.

generated from the acquired images (Figure S1). By TEM, the Cu-AmP-CPG nanocatalyst displayed a well-dispersed and uniform pattern of nanoparticles in the size range $1-20 \mathrm{~nm}$, with an average particle size of $6.4 \mathrm{~nm}$. The polydispersity index of the copper nanoparticles was calculated from the ratio of the D90 and D10 values, and was found to be 5.8 .
To assess the morphology of the Cu-AmP-CPG, SEM imaging was used and showed that the copper loading process had not led to the formation of any larger aggregates, and neither had the nanoparticle formation caused any pore blockage. As can be seen in Figure 2, the CPG support displays the same

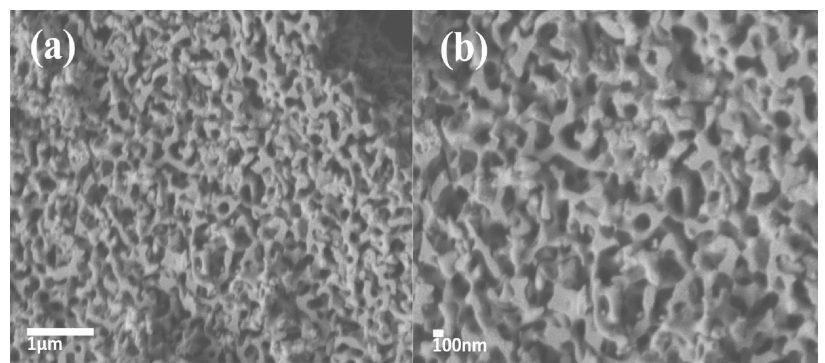

Figure 2. Different resolution SEM micrographs of the AmP-CPG support after loading of copper, a) with $1 \mu \mathrm{m}$ scale bar and b) with $100 \mathrm{~nm}$ scale bar.

macroporous morphology with wide channels and narrow necking of the pore walls both before and after the immobilization of copper nanoparticles (for SEM images of AmP-functionalized CPG, see Figure S2).

To obtain information regarding the oxidation state of the copper nanoparticles, the catalyst was analyzed by XPS. This analysis provided evidence for the presence of both $\mathrm{Cu}(\mathrm{I})$ and $\mathrm{Cu}(\mathrm{II})$ in an estimated ratio of $1.6: 1$, respectively. The high resolution spectra for the $\mathrm{Cu} 2 \mathrm{p}$ region revealed two main peaks located at $932.5 \mathrm{eV}$ and $952.6 \mathrm{eV}$ belonging to $\mathrm{Cu}(\mathrm{I})$ as well as peaks at $934.8 \mathrm{eV}$ and $955.2 \mathrm{eV}$ that are characteristic of $\mathrm{Cu}(\mathrm{II})$ (Figure S3). Moreover, the satellite features of these peaks are clearly observed at $941.1 \mathrm{eV}, 943.9 \mathrm{eV}$ and $963.0 \mathrm{eV}$, which also indicated the absence of $\mathrm{Cu}(0)$ species. Furthermore, the auger parameter (AP) was calculated to $1849 \mathrm{eV}$ using the kinetic energy of the LMM state $(916.5 \mathrm{eV}$ ) (for auger spectra of $\mathrm{Cu}$ LMM, see Figure S4) and the binding energy of Cu2p (932.5 eV), which is consistent with previous reports for $\mathrm{Cu}(\mathrm{I})$ species and clearly different from the $\mathrm{Cu}(0) \mathrm{AP}$ of $1851 \mathrm{eV}$. Collectively, these results show that the majority of the immobilized ionic $\mathrm{Cu}(\mathrm{II})$ species in the precatalyst were reduced to $\mathrm{Cu}(\mathrm{I})(61 \%) .{ }^{[14]}$ For quantification of the total copper content, inductively coupled plasma-optical emission spectroscopy (ICP-OES) was used and it measured the loading to be $3.3 \mathrm{wt} \%$.

The catalytic evaluation of the Cu-AmP-CPG nanocatalyst commenced with a screening of the reaction conditions for the aerobic oxidation of benzyl alcohol $\mathbf{1}$ a to benzaldehyde $\mathbf{2 a}$ (Table 1). Subjecting $\mathbf{1}$ a to the Cu-AmP-CPG nanocatalyst ( $5 \mathrm{~mol} \%$ ) and TEMPO ( $5 \mathrm{~mol} \%$ ) in toluene at room temperature under $\mathrm{O}_{2}$ atmosphere, resulted in $49 \%$ conversion into the desired aldehyde $\mathbf{2} \mathrm{a}$ after $48 \mathrm{~h}$ (Table 1 , entry 1 ). Significantly lower conversion was observed when the reaction was carried out in $\mathrm{MeCN}$ or $\mathrm{CH}_{2} \mathrm{Cl}_{2}$, which gave $29 \%$ and $5 \%$ conversion, respectively (Table 1, entries 2 and 3). To improve the efficiency of the catalytic protocol, the temperature was increased to $100^{\circ} \mathrm{C}$, which resulted in quantitative conversion already after $4 \mathrm{~h}$ (Table 1, entry 4). In comparison, only negligible levels of 
Table 1. Optimization of the oxidation of benzyl alcohol 1 a to benzaldehyde 2 a catalyzed by the mixed valence $\mathrm{Cu}(\mathrm{I} / \mathrm{II})-\mathrm{AmP}-\mathrm{CPG}$ nanocatalyst.

\begin{tabular}{|c|c|c|c|c|}
\hline \multicolumn{4}{|c|}{$\begin{array}{c}\mathrm{Cu}(\mathrm{I} / \mathrm{II})-\mathrm{Amp}-\mathrm{CPG} \\
(5 \mathrm{~mol} \%)\end{array}$} & \\
\hline $1 a$ & \multicolumn{3}{|c|}{ TEMPO (5 mol\%), $\mathrm{O}_{2}$} & 2a \\
\hline Entry & Solvent & $\begin{array}{l}\text { Temp. } \\
\left({ }^{\circ} \mathrm{C}\right)\end{array}$ & $\begin{array}{l}\text { Time } \\
\text { (h) }\end{array}$ & $\begin{array}{l}\text { Conv. }{ }^{[b]} \\
(\%)\end{array}$ \\
\hline $1^{[\mathrm{a}]}$ & PhMe & 22 & 48 & 49 \\
\hline $2^{[a]}$ & $\mathrm{MeCN}$ & 22 & 48 & 29 \\
\hline $3^{[a]}$ & $\mathrm{CH}_{2} \mathrm{Cl}_{2}$ & 22 & 48 & 5 \\
\hline $4^{[\mathrm{a}]}$ & PhMe & 100 & 4.0 & $>95$ \\
\hline $5^{[c]}$ & PhMe & 100 & 4.0 & $<5$ \\
\hline $6^{[\mathrm{a}]}$ & neat & 100 & 1.0 & $>95$ \\
\hline $7^{[\mathrm{a}]}$ & neat & 50 & 5.5 & 95 \\
\hline $8^{[\mathrm{d}]}$ & neat & 50 & 5.5 & $<5$ \\
\hline $9^{[e]}$ & neat & 50 & 5.5 & $<5$ \\
\hline
\end{tabular}

[a] Performed under $1 \mathrm{~atm}$. $\mathrm{O}_{2}$ with $1 \mathrm{a}, \mathrm{Cu}(\mathrm{I} / \mathrm{II})$-AmP-CPG $(5 \mathrm{~mol} \%$ of $\mathrm{Cu}$ ), and TEMPO (5 mol\%). See SI for details. [b] Determined by ${ }^{1} \mathrm{H}$ NMR spectra on the crude reaction mixture. [c] Without TEMPO and $\mathrm{Cu}(\mathrm{I} / \mathrm{II})-\mathrm{AmP}-\mathrm{CPG}$. [d] Without $\mathrm{Cu}(\mathrm{I} / \mathrm{II})$-AmP-CPG. [e] Without TEMPO.

benzaldehyde $\mathbf{2}$ a were detected for control reactions performed in the absence of $\mathrm{Cu}(\mathrm{I} / \mathrm{II})-\mathrm{AmP}-\mathrm{CPG}$ and/or TEMPO (Table 1, entries 5, 8 and 9), clearly emphasizing that both components are necessary for the observed oxidation process. The presence of additional Lewis basic ligands, as exemplified by 1-methylimidazole and 4-dimethylaminopyridine, was found to not have any beneficial effect on the reaction outcome (entries not shown). Aiming to improving the green chemistry profile of our catalytic system, we investigated if it operated efficiently under solvent-free conditions. To our delight, performing the reaction under neat conditions at $100^{\circ} \mathrm{C}$ allowed the reaction time to be reduced to $1 \mathrm{~h}$, while maintaining quantitative conversion (Table 1, entry 6). It was also possible to achieve full conversion to $2 \mathrm{a}$ at $50^{\circ} \mathrm{C}$ for the neat reaction by extending the reaction time to $5.5 \mathrm{~h}$ (Table 1 , entry 7).

With the optimized conditions in hand (neat, $50{ }^{\circ} \mathrm{C}$ ), the scope of the catalytic protocol was studied by surveying a variety of alcohols (Table 2). As demonstrated by entries 2-5, the catalytic system was also successful in the oxidation of other benzyl alcohol derivatives. The $p$-methoxy and $p$-chloro substituted aldehydes $\mathbf{2} \mathbf{b}$ and $\mathbf{2 c}$ (entries 2 and 3 ) could be obtained in $98 \%$ yield after comparable reaction times to that of the oxidation of benzyl alcohol (entry 1). For the more electron-deficient alcohols $\mathbf{1} \mathbf{d}$ and 1 e (entries 4-5), an extended reaction time was needed to reach a high yield $(80 \%$ and $85 \%$ after $10 \mathrm{~h}$, respectively). On the other hand, the
Table 2. Aerobic oxidation of alcohols $\mathbf{1}$ to carbonyl compounds $\mathbf{2}$ catalyzed by the mixed valence Cu-AmP-CPG nanocatalyst.

\begin{tabular}{|c|c|c|c|c|c|}
\hline \multirow[b]{2}{*}{ Entry } & \multirow{2}{*}{$\overbrace{1}^{\mathrm{R}_{1}} \mathrm{OH}$} & \multirow[t]{2}{*}{$\begin{array}{l}\mathrm{Cu}(\mathrm{I} / \mathrm{ll})-\mathrm{Amp}-\mathrm{CPG} \\
(5 \mathrm{~mol} \%) \\
\text { EMPO }(5 \mathrm{~mol} \%), \mathrm{O}_{2} \\
\text { Product }\end{array}$} & \multirow[t]{2}{*}{$\rightarrow$} & \multirow{2}{*}{$\mathrm{T}\left({ }^{\circ} \mathrm{C}\right)$} & \multirow[b]{2}{*}{ Yield $(\%)^{[a]}$} \\
\hline & & & & & \\
\hline 1 & & & 5.5 & 50 & 97 \\
\hline 2 & & & 5.5 & 50 & 98 \\
\hline 3 & & & 5.5 & 50 & 98 \\
\hline 4 & & & 10 & 50 & 80 \\
\hline 5 & & & 10 & 50 & 86 \\
\hline 6 & & & 5.5 & 50 & 97 \\
\hline 7 & & & 10 & 50 & $71^{[b]}$ \\
\hline $8^{[c]}$ & & & 16 & 100 & 57 \\
\hline 9 & & & 48 & 100 & 95 \\
\hline 10 & & & 48 & 100 & $89^{[b]}$ \\
\hline 11 & & & 48 & 100 & 90 \\
\hline 12 & & & 48 & 100 & 54 \\
\hline 13 & & $2 m$ & 48 & 100 & 40 \\
\hline \multicolumn{6}{|c|}{ 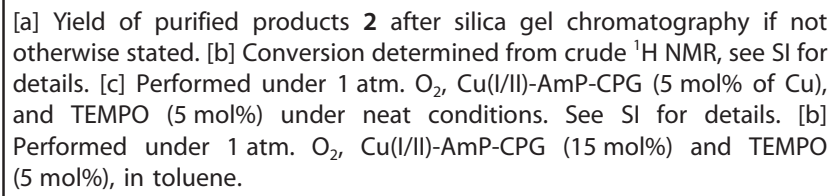 } \\
\hline
\end{tabular}

catalytic protocol proved to be more efficient for the oxidation of cinnamyl alcohol $\mathbf{1} \mathbf{f}$, giving aldehyde $\mathbf{2} \mathbf{f}$ in $\mathbf{9 7 \%}$ yield after $5.5 \mathrm{~h}$ (entry 6). Furfuryl alcohol $\mathbf{1} \mathbf{~ g}$ was also tolerated by the catalytic protocol, giving $70 \%$ conversion to $\mathbf{2 g}$ after $10 \mathrm{~h}$ (entry 7). The primary aliphatic alcohol, 1-heptanol $\mathbf{1 h}$ was found to be oxidized less efficiently, and the reaction had to be carried out with increased catalyst loading and harsher reaction conditions in toluene to give 1-heptanal $\mathbf{2} \mathbf{h}$ in $57 \%$ yield (entry 8). A noteworthy feature of this catalytic system was that it exclusively formed the aldehyde products in all cases, without any detectable amounts of the over-oxidized carboxylic acid products.

The copper nanocatalyst also proved to be quite effective for the oxidation of secondary alcohols as demonstrated by the reactions of 1-phenylethanol (1 i), 1-(4-chlorophenyl)ethanol (1 j) and 1-(4-methylphenyl)ethanol (1 k) (entries 9-11). All of these substrates were efficiently converted to their corresponding ketones when the reactions were carried out for $48 \mathrm{~h}$ at $100^{\circ} \mathrm{C}$. However, in the case of the secondary alcohols $1 \mathrm{I}$ and 
$1 \mathrm{~m}$, the oxidation were found to proceed less efficiently and only moderate yields of the corresponding ketones $\mathbf{2 l}$ and $\mathbf{2} \mathbf{m}$ were obtained (entries 12-13).

To evaluate the recyclability of the synthesized Cu-AmP-CPG nanocatalyst, it was used repeatedly for the oxidation of $\mathbf{1} \mathbf{a}$, where each cycle was performed under neat conditions at $100^{\circ} \mathrm{C}$ for $1 \mathrm{~h}$. The catalyst proved to be robust under these reaction conditions, and gave $>95 \%$ conversion over seven consecutive reaction cycles (Figure 3). ${ }^{[15]}$ Analysis of the recov-

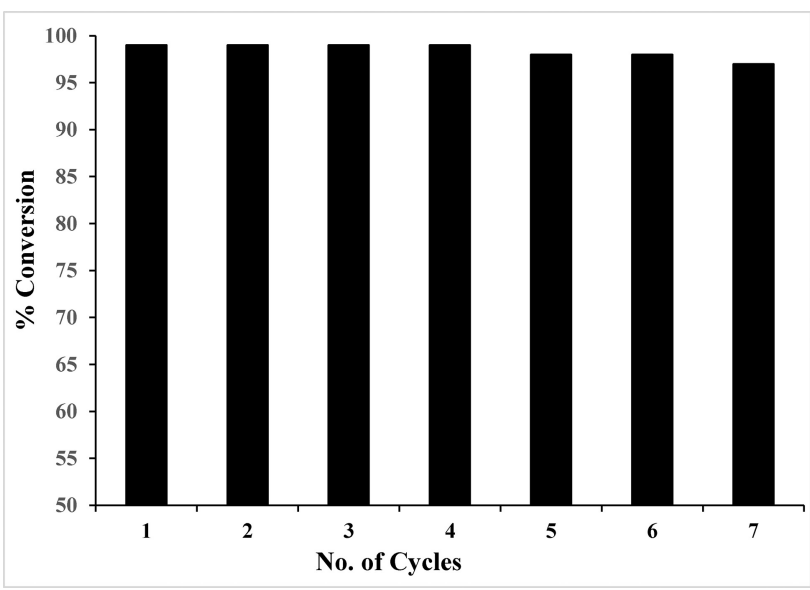

Figure 3. Aerobic oxidation of $\mathbf{1}$ a by the mixed valence Cu-AmP-CPG nanocatalyst under neat conditions at $100^{\circ} \mathrm{C}$ for $1 \mathrm{~h}$ measured over seven cycles. Conversion was determined by ${ }^{1} \mathrm{H}$ NMR analysis of the crude reaction mixture.

ered $\mathrm{Cu}-\mathrm{AmP}$-CPG nanocatalyst by EELS, revealed that the $\mathrm{Cu}$ nanoparticles maintained a similar composition of $\mathrm{Cu}(\mathrm{l})$ and $\mathrm{Cu}(\mathrm{II})$ oxidation states as before catalysis (see SI and Figure S5 for more details).

By comparing the Cu-AmP-CPG/TEMPO system with other recent aerobic alcohol oxidation protocols based on heterogeneous transition-metal catalysts, it is evident that the reported system compares well both in terms of performance and green chemistry profile. Although there exists a number of heterogenous catalytic protocols that can effeciently mediate the direct aerobic oxidation of alcohols without the need of additional electron transfer mediators, these are ofter are based on noble metals such as $\mathrm{Au}_{1}^{[16]} \mathrm{Pd}^{[16 e, 17]}$ and $\mathrm{Ru}^{[18]}$. In comparison to these heterogeneous catalysts, the reported Cu-AmP-CPG constitutes a more cost-effective alternative. Also, the reaction conditions (temperature, reaction time and catalyst loading) used for the oxidation reactions involving the Cu-AmP-CPG/ TEMPO system are competitive with those of other benchmark heterogeneous catalysts. ${ }^{[16,17,18,19]}$ Additionally, the Cu-AmP-CPG was shown to operate efficiently under solvent-free conditions, unlike some other reported heterogeneous protocols. ${ }^{[16 d, 17 a, c, e, 18 a,-}$ $b, 19 a, c-g]$ It is also important to emphasize that there also exist metal-free protocols based on nitric acid-assisted oxidation systems and TEMPO, ${ }^{[20]}$ which are also attractive systems for carrying out the oxidation of alcohols. However, by employing the Cu-AmP-CPG nanocatalyst it is possible to avoid the use of nitric acid, which could be detrimental for acid-labile substrates.
In conclusion, we have reported the synthesis of copper nanoparticles immobilized on amino-functionalized CPG and shown that they in combination with TEMPO constitute an efficient and selective catalytic system for the aerobic oxidation of alcohols to their corresponding carbonyl compounds. Characterization by XPS and various microscopy techniques revealed that the catalyst was primarily composed of 1-10 nm sized mixed $\mathrm{Cu}(\mathrm{l} / \mathrm{II})$ nanoparticles that were uniformly distributed throughout the pore system of the CPG material. The developed copper nanocatalyst displayed excellent recyclability that enabled it to be used up to seven times for the oxidation of benzyl alcohol without any significant loss in activity. Further research is currently on-going in our laboratories to identify other attractive transformations and cascade reactions that can be mediated by this low cost heterogeneous copper catalyst.

\section{Experimental Section}

Representative Procedure for the Cu(I/II)-AmP-CPG Catalyzed Catalytic Aerobic Oxidation of Benzylic Alcohol under Solvent-free Conditions

An oven-dried microwave vial $(8 \mathrm{~mL})$ equipped with a magnetic stir bar was charged with $\mathrm{Cu}(\mathrm{I} / \mathrm{II})-\mathrm{AmP}-\mathrm{CPG}(30 \mathrm{mg}, 5 \mathrm{~mol} \%$ of $\mathrm{Cu})$ and TEMPO $\left(3.84 \times 10^{-2} \mathrm{mmol}, 5 \mathrm{~mol} \%\right)$. The vial was then sealed and benzyl alcohol $1 \mathrm{a}\left(6.78 \times 10^{-1} \mathrm{mmol}\right)$ was added. The atmosphere was then changed to oxygen and an oxygen balloon was connected to the reaction vessel. The resulting mixture was allowed to stir at $50^{\circ} \mathrm{C}$ for $5.5 \mathrm{~h}$. The reaction mixture was then diluted with $\mathrm{CHCl}_{3}$, transferred to a falcon tube, and centrifuged at $4000 \mathrm{rpm}$ for an appropriate time. The supernatant was collected, concentrated in vacuo and purified by silica gel column chromatography (petroleum ether/EtOAc 20:1) to afford the corresponding product $\mathbf{2 a}$.

\section{Acknowledgements}

We gratefully acknowledge financial support from the Swedish Foundation for Strategic Research, and Stiftelsen Olle Engkvist Byggmästare. The Knut and Alice Wallenberg (KAW) Foundation is also acknowledged for an equipment grant for the electron microscopy facilities at Stockholm University. O. V acknowledges Wenner-Gren Foundations for their financial support.

\section{Conflict of Interest}

The authors declare no conflict of interest.

Keywords: alcohol oxidation - copper nanoparticles - green chemistry $\cdot$ heterogeneous catalysis $\cdot$ TEMPO

[1] a) R. H. Crabtree, The Organic Chemistry of Transition Metals, 5th ed., John Wiley \& Sons, Inc., New York, USA, 2009; b) M. Beller, C. Bolm, Transition Metals for Organic Synthesis: Building Blocks and Fine Chemicals, 2nd ed. (Wiley-VCH Verlag, Weinheim, 2008). 
[2] a) L. L. Chng, N. Erathodiyil, J. Y. Ying, Acc. Chem. Res. 2013, 46, 18251837; b) E. Gross, J. M. Krier, L. Heinke, G. A. Somorjai, Top. Catal. 2012 55, 13-23; c) H. Cong, J. A. Porco Jr., ACS Catal. 2012, 2, 65-70; d) J. D. Scholten, B. Caroline Leal, J. Dupont, ACS Catal. 2012, 2, 184-200 e) M. J. Climent, A. Corma, S. Iborra, Chem. Rev. 2011, 111, 1072-1133.

[3] a) U. Wollein, B. Bauer, R. Habernegg, N. Schramek, Eur. J. Pharm. Sci. 2015, 77, 100-105; b) A. Thayer, Chem. Eng. News 2005, 83, 55-58; c) R van Heerbeek, P. C. J. Kamer, P. W. N. M. van Leeuwen, J. N. H. Reek, Chem. Rev. 2002, 102, 3717-3756.

[4] a) R. Jin, C. Zeng, M. Zhou, Y. Chen, Chem. Rev. 2016, 116, 10346-10413 b) C. Janiak, Top. Organomet. Chem. 2015, 51, 17-53; c) M. Naghdi, M. Taheran, S. K. Brar, M. Verma, R. Y. Surampalli, J. R. Valero, Beilstein J. Nanotechnol. 2015, 6, 2354-2376; d) J. Pal, T. Pal, Nanoscale 2015, 7, 14159-14190

[5] a) P. Zhang, H. Zhu, S. Dai, ChemCatChem 2015, 7, 2788-2805; b) D. S $\mathrm{Su}$, in Nanomaterials in Catalysis, $1^{\text {st }}$ ed., edited by P. Serp, and $\mathrm{K}$. Phillipot, Wiley-VCH, Weinheim, 2013, pp. 331-374; c) L. F. Malbena, S. Sinha Ray, S. D. Mhlanga, N. J. Coville, Appl. Nanosci. 2011, 1, 67-77 d) G. G. Wildgoose, C. E. Banks, R. G. Compton, Small 2006, 2, 182-193.

[6] a) P. J. Waller, F. Gandara, O. M. Yaghi, Acc. Chem. Res. 2015, 48, 3053 3063; b) S.-Y. Ding, W. Wang, Chem. Soc. Rev. 2013, 42, 548-568;

[7] a) S. Li, K. Yang, C. Tan, X. Huang, W. Huang, H. Zhang, Chem. Commun. 2016, 52, 1555-1562; b) H.-L. Jiang, Q. Xu, Chem. Commun. 2011, 47 3351-3370; c) A. Corma, H. Garcia, F. X. Llabrés i Xamena, Chem. Rev. 2010, 110, 4606-4655.

[8] a) M. B. Gawande, P. S. Branco, R. S. Varma, Chem. Soc. Rev. 2013, 42, 3371-3393; b) V. Hulea, E. Dumitriu, in Nanomaterials in Catalysis, $1^{\text {st }}$ Ed., edited by P. Serp, and K. Phillipot, Wiley-VCH, Weinheim, 2013, pp. 375-413.

[9] a) Z. Li, J. Li, Curr. Org. Chem. 2013, 17, 1334-1349; b) D. Astruc, A Diallo, C. Ornelas, in Nanomaterials in Catalysis, $1^{\text {st }}$ ed., edited by P. Serp and K. Phillipot, Wiley-VCH, Weinheim, 2013, pp. 97-122; c) E. Guibal, Prog. Polym. Sci. 2005, 30, 71-109; d) M. Králik, A. Biffis, J. Mol. Catal. A Chem. 2001, 117, 113-138.

[10] a) B. Sun, G. Zhou, H. Zhang, Prog. Solid State Chem. 2016, 44, 1-19, b) R. Luque, A. M. Balu, M. Campelo, M. D. Gracia, E. Losada, A. Pineda, A. A. Romero, J. C. Serrano-Ruiz, Catalysis 2012, 24, 253-280; c) A Taguchi, F. Schüth, Micropor. Mesopor. Mater. 2005, 77, 1-45.

[11] a) C. Palo-Nieto, S. Afewerki, M. Anderson, C.-W. Tai, P. Berglund, A. Córdova, ACS Catal. 2016, 6, 3932-3940; b) L. Deiana, L. Ghisu, O. Córdova, S. Afewerki, R. Zhang, A. Córdova, Synthesis 2014, 46, $1303-$ 1310; c) C. Shen, Y. J. Wang, J. H. Xu, K. Wang, G. S. Luo, Langmuir 2012 28, 7519-7527; d) W. Bonrath, B. Ondruschka, C. Schmoeger, A. Stolle Int. Patent WO2010/020671 A1, 2008; Chem Abstr 2010, 152, 311257; e) K. Koutsopoulos, K. Michael Eriksen, R. Fehrmann, J. Catal. 2006, 238, 270-276; f) J. Freitag, M. Hermann, M. Nuchter, B. Ondruschka, F. Schneider, A. Stole, Optica Applicata 2005, 35, 745-752; g) J. Li, A. W.-H Mau, C. R. Strauss, Chem. Commun. 1997, 1275-1276.

[12] For selected examples, see: a) A. Porcheddu, E. Colacino, G. Cravotto, F Delogu, L. De Luca, Beilstein J. Org. Chem. 2017, 13, 2049-2055; b) M. Kongkaew, K. Sitthisuwannakul, V. Nakarajouyphon, S. Pornsuwan, P. Kongsaeree, P. Sangtrirutnugul, Dalton Trans. 2016, 45, 16810-16819; c) J. E. Steves, S. S. Stahl, J. Org. Chem. 2015, 80, 11184-11188; d) J. E. Steves, S. S. Stahl, J. Am. Chem. Soc. 2013, 135, 15742-15745; e) J. M Hoover, B. L. Ryland, S. S. Stahl, J. Am. Chem. Soc. 2013, 135, 2357-2367 f) X. Liu, Q. Xia, Y. Zhang, C. Chen, W. Chen, J. Org. Chem. 2013, 78, 8531-8536; g) J. M. Hoover, S. S. Stahl, J. Am. Chem. Soc. 2011, 133, 16901-16910; h) E. T. T. Kumpulainen, A. M. P. Koskinen, Chem. Eur. J. 2009, 15, 10901-10911; i) P. Gamez, I. W. C. E. Arends, J. Reedijk, R. A. Sheldon, Chem. Commun. 2003, 2414-2415; j) J. M. Hoover, B. L. Ryland. S. S. Stahl, ACS Catal. 2013, 3, 2599-2605. For a review, see: k) B. L. Ryland, S. S. Stahl, Angew. Chem. Int. Ed. 2014, 53, 8824-8838; Angew. Chem. 2014, 126, 8968-8983.
[13] a) X. Du, Y. Luan, F. Yang, D. Ramella, X. Shu, New J. Chem. 2017, 41, 4400-4405; b) J. Hou, Y. Luan, J. Yu, Y. Qi, G. Wang, Y. Lu, New J. Chem. 2016, 40, 10127-10135; c) J. Li, H. Gao, L. Tan, Y. Luan, M. Yang, Eur. J. Inorg. Chem. 2016, 4906-4912; d) B. R. Kim. J. S. Oh, J. Kim, C. Y. Lee, Catal. Lett. 2016, 146, 734-743; e) Y. Qi, Y. Luan, J. Yu, X. Peng, G. Wang, Chem. Eur. J. 2015, 21, 1589-1597; f) R. J. Kalbasi, A. A. Nourbakhsh, M. Zia, J. Inorg. Organomet. Polym. 2012, 22, 536-542.

[14] a) M. C. Biesinger, L. W. M. Lau, A. R. Gerson, R. St. C. Smart, Appl. Surf. Sci. 2010, 257, 887-898; b) S. Marisa, Chem Phys. Lett. 1979, 63, 52-56; c) S. Gunnar Surf. Sci. 1973, 35, 96-108; d) R. D. Leapman, L. A. Grunes, P. L. Fejes, Phys. Rev. B 1982, 26, 614-635; e) J. P. Ngantcha, M. Gerland, Y. Kihn, A. Riviere, Eur. Phys. J. Appl. Phys., 2005, 29, 83-89.

[15] In contrast, the control reaction with $5 \mathrm{~mol} \%$ TEMPO and no $\mathrm{Cu}$ nanocatalyst gave $<5 \%$ conversion after $1 \mathrm{~h}$ at $100^{\circ} \mathrm{C}$.

[16] a) S. Li, W. Li, Y. Li, G. Fan, F. Li, ChemPlusChem 2017, 82, 270-279; b) T. Mitsudome, A. Noujima, T. Mizugaki, K. Jitsukawa, K. Kaneda, Adv. Synth. Catal. 2009, 351, 1890-1896; c) J. Wang, X. Lang, Z. Bao, M. Jia, J. Wang, X. Guo, J. Zhao, ChemCatChem 2014, 6, 1737-1747; d) B. Karimi, F. K. Esfahani, Adv. Synth. Catal. 2012, 354, 1319-1326; e) D. I. Enache, J. K. Edwards, P. Landon, B. Solsona-Espriu, A. F. Carley, A. A. Herzing, M. Watanabe, C. J. Kiely, D. W. Knight, G. J. Hutchings, Science 2006, 311, 362-365; f) A. Abad, P. Concepcion, A. Corma, H. Garcia, Angew. Chem. Int. Ed. 2005, 44, 4066-4069.

[17] a) G.-J. Chen, J.-S. Wang, F.-Z Jin, M.-Y. Liu, C.-W. Zhao, Y.-A. Li, Y.-B. Dong, Inorg. Chem. 2016, 55, 3058-3064; b) V. Pascanu, A. Bermejo Gomez, C. Ayats, A. E. Platero-Prats, F. Carson, J. Su, Q. Yao, M. A. Pericas, X. Zou, B. Martin-Matute, ACS Catal. 2015, 5, 472-479; c) S. Varma, D. Tripathi, P. Gupta, R. Singh, G. H. Bahuguna, L. N. Shivakumar K, R. K. Chauhan, S. Saran, S. L. Jain, Dalton Trans. 2013, 42, 1152211527; d) E. V. Johnston, O. Verho, M. D. Kärkäs, M. Shakeri, C.-W. Tai, P. Palmgren, K. Eriksson, S. Oscarsson, J.-E. Bäckvall, Chem. Eur. J. 2012, 18, 12202-12206; e) B. Karimi, S. Abedi, J. H. Clark, V. Budarin, Angew. Chem. Int. Ed. 2006, 45, 4776-4779; f) K. Mori, T. Hara, T. Mizugaki, K. Ebitani, K. Kaneda, J. Am. Chem. Soc. 2004, 126, 10657-10666.

[18] a) P. Das, N. Aggarwal, N. R. Guha, Tetrahedron Lett. 2013, 54, 29242928; b) Y. Zhang, J. Wang, T. Zhang, Chem. Commun. 2011, 47, 53075309; c) M. Lakshmi Kantam, U. Pal, B. Sreedhar, S. Bhargava, Y. Iwasawa, M. Tada, B. M. Choudary, Adv. Synth. Catal. 2008, 350, 1225-1229; d) K. Yamaguchi, N. Mizuno, Angew. Chem. Int. Ed. 2002, 41, 4538-4542.

[19] Selected examples of heterogeneous alcohol oxidation catalysts based on earth-abundant metals: a) M. M. Kadam, K. B. Dhopte, N. Jha, V. G. Gaikar, P. R. Nemade, New. J. Chem. 2016, 40, 1436-1442; b) Y. Qi, Y. Luan, J. Yu, X. Peng, G. Wang, Chem. Eur. J. 2015, 21, 1589-1597; c) D. Baruah, U. Pratim Saikia, P. Pahari, D. Konwar, Tetrahedron Lett. 2015, 56, 2543-2547; d) X. Zhu, D. Yang, W. Wei, M. Jiang, L. Li, X. Zhu, J. You, H. Wang, RSC Adv. 2014, 4, 64930-64935; e) P. Singh Rathore, R. Patidar, S. Thakore, RSC Adv. 2014, 4, 41111-41121; f) R. J. Kalbasi, A. A. Nourbakhsh, M. Zia, J. Inorg. Organomet. Polym. Mater. 2012, 22, 536-542. g) Y.-C. Son, V. D. Makwana, A. R. Howell, S. L. Suib, Angew. Chem. Int. Ed. 2001, 113, 4410-4413.

[20] a) Y. Shi, Y. Nabae, T. Hayakawa, M. Kakimoto, RSC Adv. 2015, 5, 19231928; b) A. Rahimi, A. Azarpira, H. Kim, J. Ralph, S. S. Stahl, J. Am. Chem. Soc. 2013, 135, 6415-6418; c) Y. Kuang, H. Rokubuichi, Y. Nabae, T. Hayakawa, M. Kakimoto, Adv. Synth. Catal. 2010, 352, 2635-2642.

Manuscript received: October 19, 2017

Accepted Article published: October 31, 2017 Version of record online: November 14, 2017 